\title{
Subversive identities at the art museum: An ESL university student's experience at the National Gallery of Canada
}

\author{
Geneviève Cloutier, Awad Ibrahim, and David Pratt, University of Ottawa
}

gclou010@uottawa.ca, aibrahim@uottawa.ca,dpratt016@uottawa.ca

Abstract Art education became interwoven with cultural mediation when a university-level English language certification class was taken on a field trip to the National Gallery of Canada. This article focuses on one ESL student who locates her subversive identity as she engages with and interprets an artwork in an interview. This student's memorable, affective, and intimately personal thoughts and feelings, as we shall see, expose the semiotic and pedagogical importance of employing strategies that honour students' identities and lived experiences. The authors call for more research in what they refer to as 'critical ESL art museum education'.

Keywords: ESL; language learning; culture; art museum education; subversive identities; pedagogy; affect.

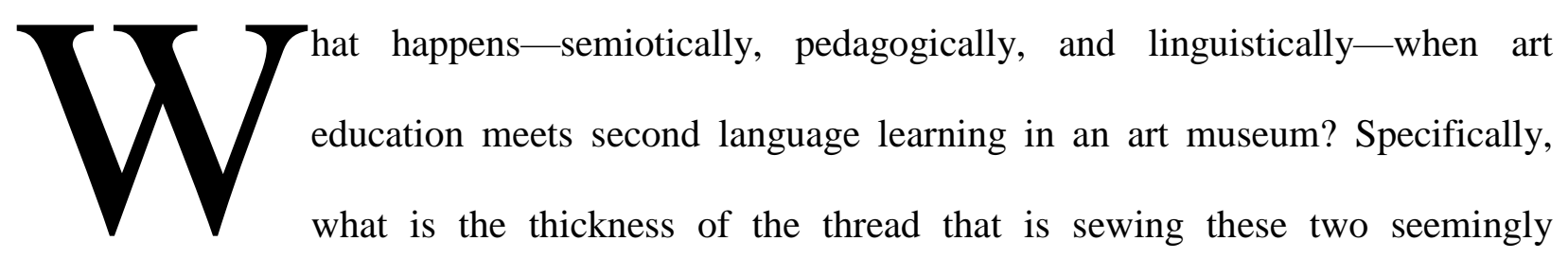

unrelated fields together? The story of these questions, we are arguing, is yet to be told. In this short essay, we hope to contribute to the limited literature linking second language learning, art museums, and pedagogy (Shoemaker, 1998). ${ }^{1}$ Art education, as we shall see, becomes interwoven with cultural mediation when a university-level English language certification class was taken on a field trip to the National Gallery of Canada. This was done to address an inadequate system whereupon textbooks dictate what types of conversations language learners have, where there is limited space for open readings, and where personal investment is not encouraged (Alim, 2011; Norton \& Toohey, 2004). Affective investment—namely 'what' we learn, 'how' we learn it, and 'why' (Ibrahim, 2006) — is of paramount importance, especially in

\footnotetext{
${ }^{1}$ For practical and pedagogical approaches linking second language learning and art museum, see:

1) http://americanhistory.si.edu/blog/2009/10/using-objects-with-english-language-learners.html

2) http://www.getty.edu/education/teachers/classroom_resources/curricula/esl3/
} 
second language learning contexts. As Shier argues (1990), the ability to "express personal thoughts and feelings" (p. 301) is central to 'why' we pedagogically and affectively invest into 'what' we learn and 'how' we learn it. In his work in Canada, Ibrahim (2006) addresses 'affective investment' by showing how and why a group of refugee and immigrant continental African students learn not English as a Second Language (ESL), but Black English as a Second Language (BESL). Through this, Ibrahim explores the direct link between identity, affective investment, and the process of second language learning. Ibrahim concludes that these students learned BESL, which they accessed in and through Black popular culture, namely Hip-Hop culture and music. BESL learning here, it is important to note, is neither a haphazard act nor without its politics or pedagogical implications. More generally, people invest where they see themselves mirrored, and this was certainly the case with these continental African students. In the end, Hip-Hop emerged for these students as a site of identity and pedagogical investment. Therefore, as Shier (1990) argues, in this context, it "becomes [pedagogically] essential that L2 instruction addresses the affective needs of learners" (p. 301). We argue that this is possible through the arts.

By bringing this debate to art education, we contend that it contains not only radical possibilities for language learning, but also for initiating, supporting, and sustaining language learners' "subversive identities." Similar to Canagarajah (2004), we define "subversive identities" as those identities that are formed not within dominant discourses, but within the margins; identities that are uniquely individualized, full of agency and desire, and savvy enough to work through (Derrida, 2000) dominance, surveillance, and authority. As a result, these identities tend to be multiple, negotiated, contingent, and forever "to become" (Deleuze \& Guattari, 1987). Those who possess subversive identities know the limit of their cultural space, 
so they dare to push that limit by engaging other cultural spaces. As we shall see, this is certainly the case with our research participant. Our participant's Middle Eastern and Muslim background ${ }^{2}$ offers cultural and social contexts that shape her reading of the art museum. Here, it is noteworthy, the research participant was able to work through the vernacular of her own community and culture while moving through a new cultural context.

For us, art museums are sites that open up critical possibilities to explore a significant intersection between language, identity, and culture in ESL education. Indeed, much has been written about art education and ESL education separately, but there is a limited amount of research regarding how these fields converge. The aim of the present paper, then, is: 1) to argue for what we call 'critical ESL art museum education', 2) to explore our participant's experiences and narratives related to subversive identities, and 3) to inquire into pedagogical strategies for art museum settings that will honour all students, specifically the identities and lived experiences of ESL students.

The study was purely qualitative in nature and was conducted with a group of twentyfour ESL students who were attending an advanced-level ESL program at a large university in northeastern Ontario, Canada. The research revolves around a field trip to the National Gallery of Canada in the summer of 2013. Two researchers were present: one as an ESL teacher, and one as an artist-researcher. Using interpretive frameworks (Emery, 2002), the artist-researcher introduced students to strategies and ways to 'read' art. This was done a week prior to the museum visit. By exploring 'how to' read art, our aim was to give the students a 'language' (in a

\footnotetext{
${ }^{2}$ For us, being mindful of essentialism and Orientalism, these descriptors are cited with trepidation. We are citing them with a strong caveat that Nahid, and all our research participants, have agency and make personal choices that in some cases are in line with the cultural framework, but not necessarily all the time. We are also mindful that 'Muslim Middle Eastern background' may be read as ethnic lumping (Ibrahim, 2014), but there is no research or language without limitations. We think the reader might find it useful to know that Nahid is an Arabic speaker and comes from Saudi Arabia.
} 
broad sense) to begin to interpret art on their own. While some of the language used may have been advanced, efforts were made to ensure the presentation was accessible with the use of images and historical references. Upon introducing them to the formalist interpretive framework, deconstruction as an interpretive framework, a gender-based interpretive framework, a cultural interpretive framework, a semiotic framework, a psychoanalytic framework, and a social realist interpretive framework (see Emery, 2002), we concluded that the students were attracted to a variety of frameworks. Indeed, through exploring a wide range of perspectives, we wanted them to have autonomy in the art museum. Similar to Duke (2010), we think "learning from an experience requires the visitor to structure inquiries for himself or herself, rather than jumping through hoops that have been pre-arranged, as they are in a conventional lesson" (p. 272). In this way, introducing them to a variety of methods proved to be useful. While our directions were open-ended, from the art museum experience, the students were asked by their instructor to choose one work of art to be discussed in future assignments, including a written reflection and an oral presentation.

We interviewed six students for this research. We asked them a multiplicity of questions about their feelings and concerns relating to the art museum; their most memorable moment or artwork; and whether the works connected to any of their personal memories, among other questions. This was achieved through a semi-structured interview with each student. For the purpose of this article, because we want to explore the readings of one specific artwork, we focus on the experiences of Nahid. This particular student was chosen for two reasons: 1) because of her willingness and ability to share, and 2) because of the scope and richness of the narratives she provided.

Regarding the course assignments, Nahid chose works that she felt she could decode- 
metaphorically, semiotically, and logically. After conducting interviews, however, we acknowledged a tension between what she was drawn to affectively and what she could analyze semiotically. While she chose works that she could analyze for the assignments, different art was discussed in depth during the interview. It became clear, first, that Nahid avoided writing and talking about works she felt were too political and/or personal. Stuart Hall's (2013) 'circuit of culture' might give us clues as to why she avoided the personal and the political. In the circuit of culture, identity, representation, production, consumption, and regulation are all interconnected. Identity is directly related to how one 'reads' and makes sense of (consumption) a work of art (representation) and how one talks about that work of art (production). For Hall, all is regulated. This became evident, too, as our participant spoke about regulation relating to artistic representations in her home country, whereupon, for instance, as we will discuss later, the human figure cannot be portrayed representationally. Nahid used her cultural and social background not to offer a 'right' and 'wrong' way of art reading, but to semiotically engage/read the art pieces; thus, she ended up avoiding the personal and the political.

It is worth reiterating that there were two factors that shaped and influenced, not to say determined, the student's reading in the art museum and what she chose to present for class assignments. The first was Nahid's limited command of the English language, and the second was how much of her Middle Eastern and Muslim backgrounds she had to negotiate as she spoke publicly; that is to say, how much she was willing to share to avoid backlash or feeding into the hysteria of Arabophobia and Islamophobia, that we see now.

Although Nahid did not select works she had a large personal investment in for course assignments, the interview process made her feel comfortable enough to express nuanced accounts of her experience. Through the interview, we found that the art museum became an 
"opportunity to encounter interpretation itself, to heed the elusive, shadowy repertoires of meaning-making that shape the thoughts, opinions, ideas, and actions we call our own" (Meszaros, 2008, p. 240). This is crucial within the ESL context, because as Canagarajah (2004) notes, "what motivates the learning of a language is the construction of the identities we desire and the communities we want to join in order to engage in communication and social life" (p. 117). With that, we contend that the art museum is a particularly pertinent site for ESL education as it creates and facilitates spaces for these cultural interpretations to be expressed. Creating and finding this space was a founding inspiration for our research project.

In our interview, the student revealed that the particular environment that the researcher and teacher created in the museum space enabled a safe space for interactions; "whereupon subversive identities can be expressed"(Canagarajah, 2004, p. 124). Like Canagarajah, we contend that this is where subversive identities can manifest. In this space, research participants were comfortable enough to negotiate codes that related to their own lived experiences, and were able to offer their own personal affective responses to the works that moved them the most. For us, this is where they located their subversive identities because they were negotiating and offering multiple perspectives to the codes of their cultural backgrounds. In both instances, Nahid displayed complicated conversations (Pinar, 2000) in relation to her Muslim cultural context. The conversations resonate with us as subversive because they demonstrate complexity. They contest one-sided formations of Middle Eastern identity, as well as one-sided portrayals of Islam found in the West (Canagarajah, 2004).

The art museum was juxtaposed against the power-laden site of the school. It invited multiple perspectives on contentious topics of identity formation, which we argue, is crucial for language development and a space for subversive identities to emerge. While we work through 
the meaning of subversive identities, we follow Canagarajah, who does not offer an explicit definition. Rather, to him, subversive identities question "the pressures of cultural production and ideological conformism in the institutional context" as well as adopt "competing identities" (Canagarajah, 2004, p. 127). The latter is particularly crucial to our study, as we shall see, as our participant engages with multiple affective responses to the complexity of her identity formation.

Nahid's interpretations offer insights into cultural complexity as she reads sculptures of Muslim women as a Muslim woman herself. Processes of interpretation led to dynamic discussions. Through her affective investment in the target language, we came to know more about the student's identities, about the communities she aspired to belong to, about the world she saw before her, and within her-what is in between. Affective investment is a way to talk about how and why we invest into where we see ourselves mirrored, thus, turning language learning into "an extension of interest in identity" targeting "the imagined communities that language learners aspire to when they learn a new language" (Norton \& Toohey, 2004, p. 48). In this way, in relation to those who wish to educate in the art museum, it is important to "recognize that not all art knowledge is found outside of [the self]" (Kalin, Grauer, Baird, \& Meszaros, 2007, p. 202). In other words, affective investment in art reflects thoughts, ideas, and actions that we call our own.

\section{"No details, no eyes...Why is she...": The Cosmos of Nahid}

Nahid, an eighteen-year-old Middle Eastern female artist with an undergraduate degree in fine arts from her home country thought that going to the National Gallery of Canada was exciting because she could see many different "kinds of art," as she put it. She specified that she was interested in seeing art that is produced "without any policy or strict rules." She explained that artistic representations of people cannot be displayed in her country. The work found in 
public museums where she is from is, in a curatorial sense, historically driven.

Nahid chose to present one of Salvador Dali's paintings for her class oral and written assignments. She loved that he creates paintings inside paintings. She spoke about his technique, his use of colour, and about how she believes that his style remains timeless - that it will never look old. She was surprised that his work is not included in the contemporary section: a section that she loves. However, she too, when asked what her most memorable work was, did not focus on her selection for the course assignments. The interview, rather, mostly focuses on Colleen Wolstenholme's work titled Triad (Figure 1). What follows is an excerpt from our conversation with Nahid regarding Coleen Wolstenholme's work:

Nahid: For me, the Afghanist women, the statues, the three women... I was happy because, well, there are no details, no hands, no mouths, but they love the outfit for Afghani woman and they influence her arts. This is why it was interesting. Interviewer: She wasn't an Afghani artist, but rather a Canadian one. Nahid: Yes this is why I found it interesting, because there is no details, no eyes... Why is she...

Interviewer: Yeah why do you think a woman would make sculptures of Afghani women without...

Nahid: Because it's unique. They don't have it in here, in Canada. And for them, or for her, it's interesting. But for me it's common, yea. Many women wear the same outfit.

Interviewer: I wondered about what you thought of that piece.

Nahid: Yes I found it interesting because they introduce our religion with a nice way. Not in a bad way, like, look they're bad. They introduce it in a good way, with a 
white colour, like angels.

Interviewer: Oh yeah... it was just plaster.

Nahid: Yes it looked like angels.

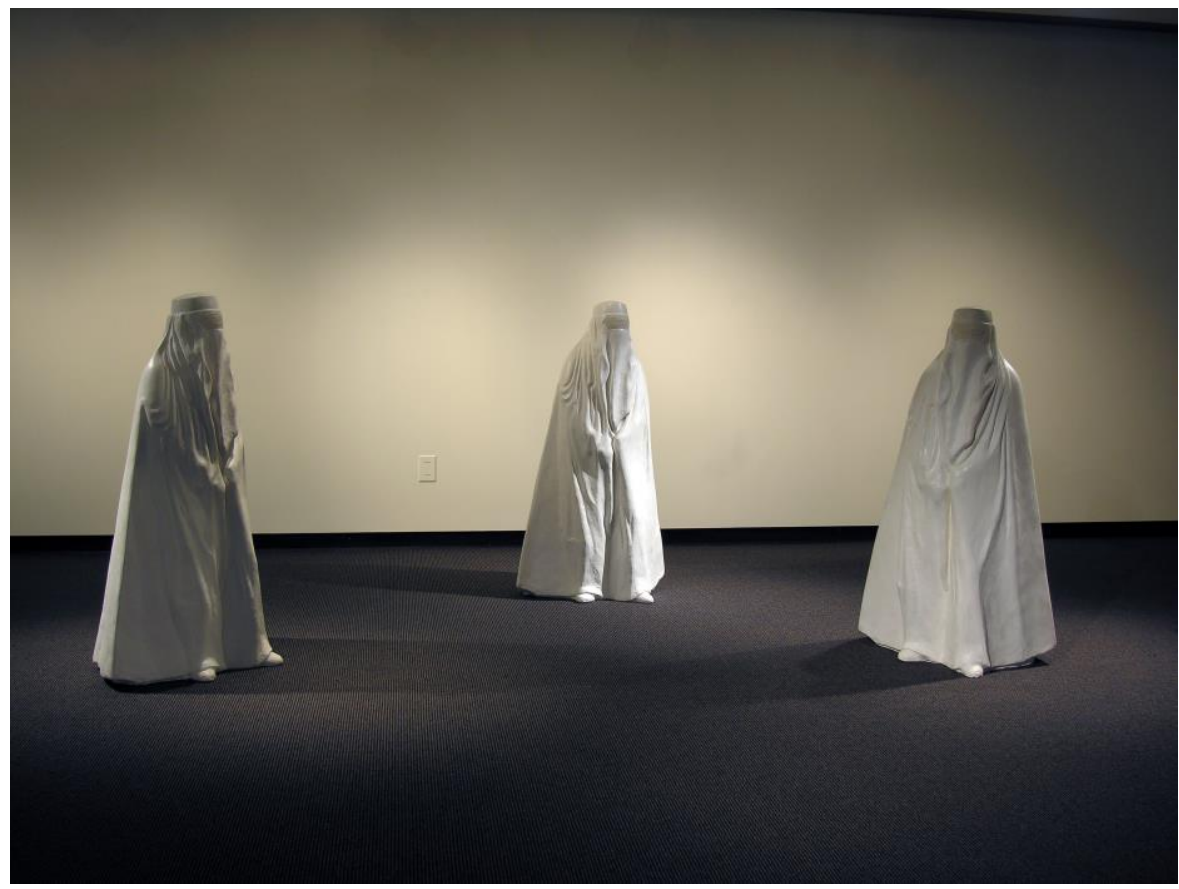

Figure 1. Colleen Woltenhome, Triad, 2005.

Nahid saw the piece as a positive depiction of the burqa, even an angelic one. She speaks about the sculptures as an "introduction" to Islam. Given her agency, and the historical moment at the time, she found the work to be beautiful, serene, "good." However, as with all artwork, to open it for semiotic reading is to open it up for multiple interpretations. Art critic, Virginia MacDonnell Eichhorn (2006), for example, has an enormously different interpretation of Triad. MacDonnell Eichhorn writes:

Wolstenholme created three burqa-clad women who are slightly smaller than lifesize. The figures are placed in a circular arrangement but are facing away from oneanother. There is a disconnect between them and their reluctance to look toward each other for support, creating a strong atmosphere of isolation. We cannot help 
but wonder at the source of isolation. Is it shame? Is it reluctance to admit the need for another's help? Is it fear of breaking out of imposed boundaries and expectations? The figures in Triad are vulnerable and helpless, imprisoned within the plaster folds of their burqas, unable to progress or move. They are incapacitated. (p. 40)

Alongside these radically different interpretations, it is clear that the meaning does not solely lie in the object. Within the context of Triad, shifts in meaning are bound to occur depending on who is reading it, when, where, and how. In this way, as researchers, we venture to suggest that Nahid did not choose the Triad for her class project because she recognized the muddiness of semiotic interpretations related to her culture, especially within the streams of discourses about women in Islam; so she chose an artwork that she perceived to be more stable in meaning.

By disrupting the notion of stable meaning in our interview with her, however, Nahid took us to a "whole nother level" (Ibrahim, 2009, p. 233), where the very category of 'language' was opened up and transformed from a simplistic morphological and syntactic category to a semiotic one. Here, the image becomes a 'text' that speaks so loudly, and it does so in polyvocality, which makes both Nahid and MacDonnall Eichhorn's readings plausible, and yet, Nahid's words remind us of "the problem of speaking for others" (Alcoff, 1992, p. 5). Indeed, this happens when art museum education meets second language learning. By engaging the art museum as a pedagogical site, as we saw, the range of identities that are available to language learners expands in infinite ways.

\section{[In]conclusion}

Although Nahid did not necessarily select her most memorable artwork for the course 
assignment, she reminds us of the complex conversations that are to be had at sites of cultural mediation. After many uninspiring discussions born out of ESL textbooks, we identify an interesting pedagogical space that has a potential for language learning, identity formation, and rich artistic expression. Those spaces that we have had the privilege of sharing remind us of the importance of time, openness, and reciprocity that can be, at times, difficult to achieve under the reality and need for assessment and evaluation. With that, however, we declare a call to action to educators and researchers to move beyond traditional course assignments. Our research points to what is missed when ESL students do not feel as though their affective accounts can be expressed.

We must always be aware of the subversive identities that do not get heard. They are there, before us. At the National Gallery of Canada, students' cross-cultural connections and interpretations were made new. Subversive identities produced ever-changing resistances to onesided forms of interpretation. Nahid worked through (Derrida, 2000) Wolstenholme's Triad alongside processes of cultural mediation. With this approach, the art museum becomes a catalyst for a critical ESL education; mediated by infinite possibilities of interpretation. When the art museum meets language learning, the world becomes fertile with radical possibilities of identity formation and critical pedagogies.

For this critical pedagogy to take place, Freire (1970) argues that we need to link students' words with their world. For us, this is where subversive identities emerge. To do otherwise, as we see in this article, is to sentence students to complete boredom and disengagement. Once Nahid was taken to the art museum, a new and radical space opened up, one where she was able to engage who she was - crucial parts of her identities - and what she knew, and she eventually spoke a 'language' (the language of the art) she was familiar with. 
Words meant something more than a simple dictionary search. We as teachers were able to link students' words with their world, on the one hand, and their identities, affective investment, and language learning, on the other. [In]conclusion (Morawski \& Palulis, 2009), it is high time that we dismiss any notion that art is too difficult for ESL students. Nahid debunks this objection. We contend that the conclusion has yet to be seen, hence the term '[in]conclusion,' and call for more research in this area. Nahid and the many students we spoke to showed us what can happen when we deploy critical pedagogy as teachers and link art museum with second language education.

\section{References}

Alcoff, L. (1992). The problem of speaking for others. Cultural Critique, 20, 5-20.

Alim, S. (2011). Globla ill-literacies: Hip-Hop cultures, youth identities, and the politics of literacy. Review of Research in Education 35(11), 120-146.

Canagarajah, S. (2004). Subversive identities, pedagogical safehouses, and critical learning. In B. Norton \& K. Toohey (Eds.), Critical pedagogies and language learning (pp. 116-137). Cambridge: Cambridge University Press.

Deleuze, G., \& Guattari, F. (1987). Thousand Plateaus: Capitalism and Schizophrenia. London: Continuum.

Derrida, J. (2000). Of hospitality. Stanford, CA: Stanford University Press.

Duke, L. (2010). The museum visit: It's an experience, not a lesson. Curator: the Museum Journal, 53(3), 271-279.

Emery, L. (2002). Teaching art in a postmodern world: Theories, teacher reflections and interpretive frameworks. Altona, Australia: Common Ground Publishing.

Freire, P. (1970). Pedagogy of the oppressed. New York: Continuum.

Hall, S. (2013). The work of representation. In S. Hall, J. Evans, \& S. Nixon (Eds.), 
Representation ( $2^{\text {nd }}$ ed.) (pp. 1-59). Los Angeles, CA: Sage.

Ibrahim, A. (2006). Becoming black: Rap and hip hop, race, gender, identity, and the politics of ESL learning. In P. Matsuda, M. Cox, J. Jordan, \& C. Ortmeier-Hooper (Eds.), Secondlanguage writing in the composition classroom: A critical sourcebook (pp. 131-148). New York: St. Martin's.

Ibrahim, A. (2009). Takin Hip-Hop to a whole nother level: Métissage, affect and pedagogy in a Global Hip-Hop Nation. In S. Alim, A. Ibrahim, \& A. Pennycook (Eds.), Global linguistic flows: Hip-Hop cultures, youth identities, and the politics of language (pp. 231248). London \& New York: Routledge.

Kalin, N., Grauer, K., Baird, J., \& Meszaros, C. (2007). Provoking points of convergence: Museum and university collaborating and co-evolving. International Journal of Art \& Design Education, 26(2), 199-205.

MacDonnell Eichhorn, V. (2006). Colleen Wolstenholme: Iconophobia. Espace: Art actuel, 77, 40.

Meszaros, C. (2008). Un/Familiar. Journal of Museum Education, 33(3), 239-246.

Morawski, C., \& Palulis, P. (2009). Auto/ethno/graphies as teaching lives: An aesthetics of difference. Journal of Curriculum Theorizing, 25(2), 6-24.

Norton, B., \& Toohey, K. (2004). Critical pedagogies and language learning. Cambridge: Cambridge University Press.

Pinar, W. F. (2000). Strange fruit: Race, sex, and an autobiographics of alterity. In P. Trifonas (Ed.), Revolutionary pedagogies: Cultural politics instituting education, and the discourse of theory (pp. 30-46). New York: Routledge.

Shier, J. H. (1990). Integrating the arts in the foreign/second language curriculum: Fusing the 
affective and the cognitive. Foreign Language Annals, 23(4), 301-314.

Shoemaker, M. K. (1998). "Art is a wonderful place to be": ESL students as museum learners. Art Education, 51(2), 40-45. 